\title{
A Cohort of Patients with COVID-19 in a Major Teaching Hospital in Europe
}

\author{
Alberto M. Borobia 1,*(D), Antonio J. Carcas 1,*, Francisco Arnalich ${ }^{2} \mathbb{D}$, Rodolfo Álvarez-Sala ${ }^{3}$, \\ Jaime Monserrat-Villatoro ${ }^{1}$, Manuel Quintana ${ }^{4}$, Juan Carlos Figueira ${ }^{4}$, \\ Rosario M. Torres Santos-Olmo ${ }^{5}$ (D), Julio García-Rodríguez ${ }^{6}$, Alberto Martín-Vega ${ }^{7}$, \\ Antonio Buño ${ }^{8}$, Elena Ramírez ${ }^{1}$ (D), Gonzalo Martínez-Alés ${ }^{9}$, Nicolás García-Arenzana ${ }^{10}(\mathbb{D}$, \\ M. Concepción Núñez ${ }^{11}$, Milagros Martí-de-Gracia ${ }^{12}$, Francisco Moreno Ramos ${ }^{13}$, \\ Francisco Reinoso-Barbero ${ }^{14}$, Alejandro Martin-Quiros ${ }^{5}$, Angélica Rivera Núñez ${ }^{5}$, \\ Jesús Mingorance ${ }^{6}$ (D) Carlos J. Carpio Segura ${ }^{3}$, Daniel Prieto Arribas ${ }^{8}$, Esther Rey Cuevas ${ }^{15}$, \\ Concepción Prados Sánchez ${ }^{3}$, Juan J. Rios ${ }^{2}$, Miguel A. Hernán ${ }^{16}$, Jesús Frías ${ }^{1}$, José R. Arribas ${ }^{2, *}$ \\ and on behalf of the COVID@HULP Working Group ${ }^{\dagger}$
}

1 Clinical Pharmacology Department, La Paz University Hospital-IdiPAZ, Universidad Autónoma de Madrid, 28046 Madrid, Spain; jaime.monserrat@salud.madrid.org (J.M.-V.); elena.ramirezg@uam.es (E.R.); jesus.frias@uam.es (J.F.)

2 Internal Medicine Department, La Paz University Hospital-IdiPAZ, Universidad Autónoma de Madrid, 28046 Madrid, Spain; farnalich@salud.madrid.org (F.A.); juanj.rios@salud.madrid.org (J.J.R.)

3 Pneumology Department, La Paz University Hospital-IdiPAZ, Universidad Autónoma de Madrid, 28046 Madrid, Spain; rodolfo.alvarezsala@salud.madrid.org (R.Á.-S.); carlosjavier.carpio@salud.madrid.org (C.J.C.S.); m.concepcion.prados@salud.madrid.org (C.P.S.)

4 Intensive Care Unit, La Paz University Hospital-IdiPAZ, Universidad Autónoma de Madrid, 28046 Madrid, Spain; manuel.quintana@salud.madrid.org (M.Q.); juancarlos.figueira@salud.madrid.org (J.C.F.)

5 Emergency Department, La Paz University Hospital-IdiPAZ, Universidad Autónoma de Madrid, 28046 Madrid, Spain; rosario.torres@salud.madrid.org (R.M.T.S.-O.); amquiros@salud.madrid.org (A.M.-Q.); angelica.rivera@salud.madrid.org (A.R.N.)

6 Microbiology Department, La Paz University Hospital-IdiPAZ, 28046 Madrid, Spain; jgarciarodriguez@salud.madrid.org (J.G.-R.); jesus.mingorance@idipaz.es (J.M.)

7 CSUR Coordination, La Paz University Hospital-IdiPAZ, 28046 Madrid, Spain; amartinv@salud.madrid.org

8 Laboratory Medicine Department, La Paz University Hospital-IdiPAZ, 28046 Madrid, Spain; antonio.buno@salud.madrid.org (A.B.); dprietoa@salud.madrid.org (D.P.A.)

9 Department of Epidemiology, Columbia University Mailman School of Public Health, New York, NY 10032, USA; gm2794@cumc.columbia.edu

10 Preventive Medicine Department, La Paz University Hospital-IdiPAZ, 28046 Madrid, Spain; ngarciaarenzana@salud.madrid.org

11 Risk Prevention Department, La Paz University Hospital-IdiPAZ, 28046 Madrid, Spain; mnunezl@salud.madrid.org

12 Emergency Radiology Unit, La Paz University Hospital-IdiPAZ, 28046 Madrid, Spain; milagros.marti@salud.madrid.org

13 Pharmacy Department, La Paz University Hospital-IdiPAZ, 28046 Madrid, Spain; fmorenor.hulp@salud.madrid.org

14 Anesthesiology Department, La Paz University Hospital-IdiPAZ, 28046 Madrid, Spain; francisco.reinoso@salud.madrid.org

15 Nursing Department, La Paz University Hospital-IdiPAZ, 28046 Madrid, Spain; esther.rey@salud.madrid.org

16 Departments of Epidemiology and Biostatistics, Harvard T.H. Chan School of Public Health, Harvard-MIT Division of Health Sciences and Technology, Boston, MA 02115, USA; mhernan@hsph.harvard.edu

* Correspondence: alberto.borobia@salud.madrid.org (A.M.B.); antonio.carcas@uam.es (A.J.C.); joser.arribas@salud.madrid.org (J.R.A.); Tel.: +34-917277000 (A.M.B. \& A.J.C. \& J.R.A.)

+ A complete list of the members of the COVID@HULP Working Group is provided in the Supplementary Materials. 


\begin{abstract}
Background: Since the confirmation of the first patient infected with SARS-CoV-2 in Spain in January 2020, the epidemic has grown rapidly, with the greatest impact on the region of Madrid. This article describes the first 2226 adult patients with COVID-19, consecutively admitted to La Paz University Hospital in Madrid. Methods: Our cohort included all patients consecutively hospitalized who had a final outcome (death or discharge) in a 1286-bed hospital of Madrid (Spain) from 25 February (first case admitted) to 19 April 2020. The data were manually entered into an electronic case report form, which was monitored prior to the analysis. Results: We consecutively included 2226 adult patients admitted to the hospital who either died (460) or were discharged (1766). The patients' median age was 61 years, and $51.8 \%$ were women. The most common comorbidity was arterial hypertension (41.3\%), and the most common symptom on admission was fever $(71.2 \%)$. The median time from disease onset to hospital admission was 6 days. The overall mortality was $20.7 \%$ and was higher in men $(26.6 \%$ vs. $15.1 \%)$. Seventy-five patients with a final outcome were transferred to the intensive care unit (ICU) (3.4\%). Most patients admitted to the ICU were men, and the median age was 64 years. Baseline laboratory values on admission were consistent with an impaired immune-inflammatory profile. Conclusions: We provide a description of the first large cohort of hospitalized patients with COVID-19 in Europe. Advanced age, male sex, the presence of comorbidities and abnormal laboratory values were more common among the patients with fatal outcomes.
\end{abstract}

Keywords: COVID19; SARS-CoV-2; Spain; Europe

\title{
1. Introduction
}

As of this writing, Spain has the second highest number of confirmed severe acute respiratory coronavirus 2 (SARS-CoV-2) infections worldwide after the United States. The first infection in Spain was confirmed on 31 January 2020, in La Gomera in the Canary Islands [1]. In the Madrid region, the first infection was registered on 25 February 2020. Madrid is a densely populated area with 6.7 million inhabitants [2] and has felt the greatest impact from the pandemic in Spain. The number of confirmed cases in Madrid was 58,819 as of 25 April (26.3\% of cases in Spain) [3], reaching a peak of 3419 new cases on 30 March.

The progression of the outbreak in Madrid is similar to that observed in the most affected areas in Western countries, such as the Lombardy region in Italy and New York City in the US. The healthcare systems of these regions are under massive stress, and the cumulative COVID-19 mortality per 100,000 inhabitants since the start of the pandemic has been high: 132 deaths in Lombardy, 140 in New York City and 190 in Madrid (as of 25 April) [4-6].

The La Paz University Hospital is a large teaching hospital with a catchment area of 527,366 inhabitants in the north of Madrid. Shortly after the outbreak, the hospital's procedures were adapted to cope with the rise in COVID-19 cases. By 25 April, the hospital had admitted over 2500 patients with COVID-19, one of the largest single-site cohorts in Europe. These patients' clinical information was collected using a standardized protocol.

In this article, we describe the first 2226 adult patients consecutively admitted with a confirmed diagnosis of SARS-CoV-2 infection to La Paz University Hospital and who had died or been discharged by 19 April. 


\section{Methods}

\subsection{Study Population}

Our study included all individuals, 18 years or older, who were hospitalized in the wards (or emergency department, due to the lack of available beds in the wards) of La Paz University Hospital with a diagnosis of COVID-19 and who either died or were discharged by 19 April. Patients discharged from the emergency department after a stay of less than $24 \mathrm{~h}$ were not considered hospitalized and were not included in this analysis.

\subsection{Data Collection}

We employed a modified version of the electronic case record form (eCRF) for severe acute respiratory infections, developed by the World Health Organization/International Severe Acute Respiratory and Emerging Infection Consortium [7]. Our eCRF includes 372 variables, grouped into demographics, medical history, infection-exposure history, symptoms, complications, treatments (excluding clinical trials) and disease progression during hospitalization (see Supplementary Material).

We collected the clinical data directly extracting the information from the hospital's database, when possible, or by a manual and individual review of the patients' electronic clinical records, including the clinical notes (DXC-HCIS- Healthcare Information System). The clinical data collected at hospital admission included age, sex, smoking status, transmission, comorbidities, symptoms on admission, respiratory status and time from disease onset. Complications during hospitalization and intensive care unit (ICU) admission were also recorded. The data collection effort was conducted by a volunteer team of resident doctors and senior medical students. Data monitoring was conducted by our hospital's Central Clinical Research Unit.

Laboratory results (hematology, biochemistry, microbiology) were extracted from various hospital data management systems, and information regarding the drugs used during hospitalization was extracted from the electronic prescription system.

\subsection{Statistical Analysis}

Continuous variables are presented as means and standard deviations (SD) or medians and interquartile ranges (IQR), and categorical variables are listed as numbers and percentages (\%). To analyze predictors of in-hospital death, we employed a multivariate logistic regression model. We selected the variables for inclusion in the model on the basis of previous findings and considering the total number of deaths in our study to avoid overfitting the model. In a sensitivity analysis to explore potential collider bias, we restricted the fit of the model to patients admitted before 20 March (results did not materially change). We performed the statistical calculations using R (version 3.4.0) [8].

The study was approved by the Research Ethics Committee of La Paz University Hospital (PI-4072) and by the Spanish Agency of Medicines and Medical Devices (HUL-AIN-2020-01) and was registered in the European Union Electronic Register of Post-Authorization Studies (EUPAS34331).

\section{Results}

A total of 3127 patients were consecutively treated in the emergency department of La Paz University Hospital between 25 February and 19 April 2020. Of these, 2226 adult patients were hospitalized and either died (460, 20.7\%) or were discharged (1766, 79.3\%) and were therefore included in our analysis. Figure 1 shows the bed occupancy by patients with COVID-19 over time, with a peak of 1033 beds, 106 of which were in the ICU (compared with 30 ICU beds before the COVID-19 pandemic). 


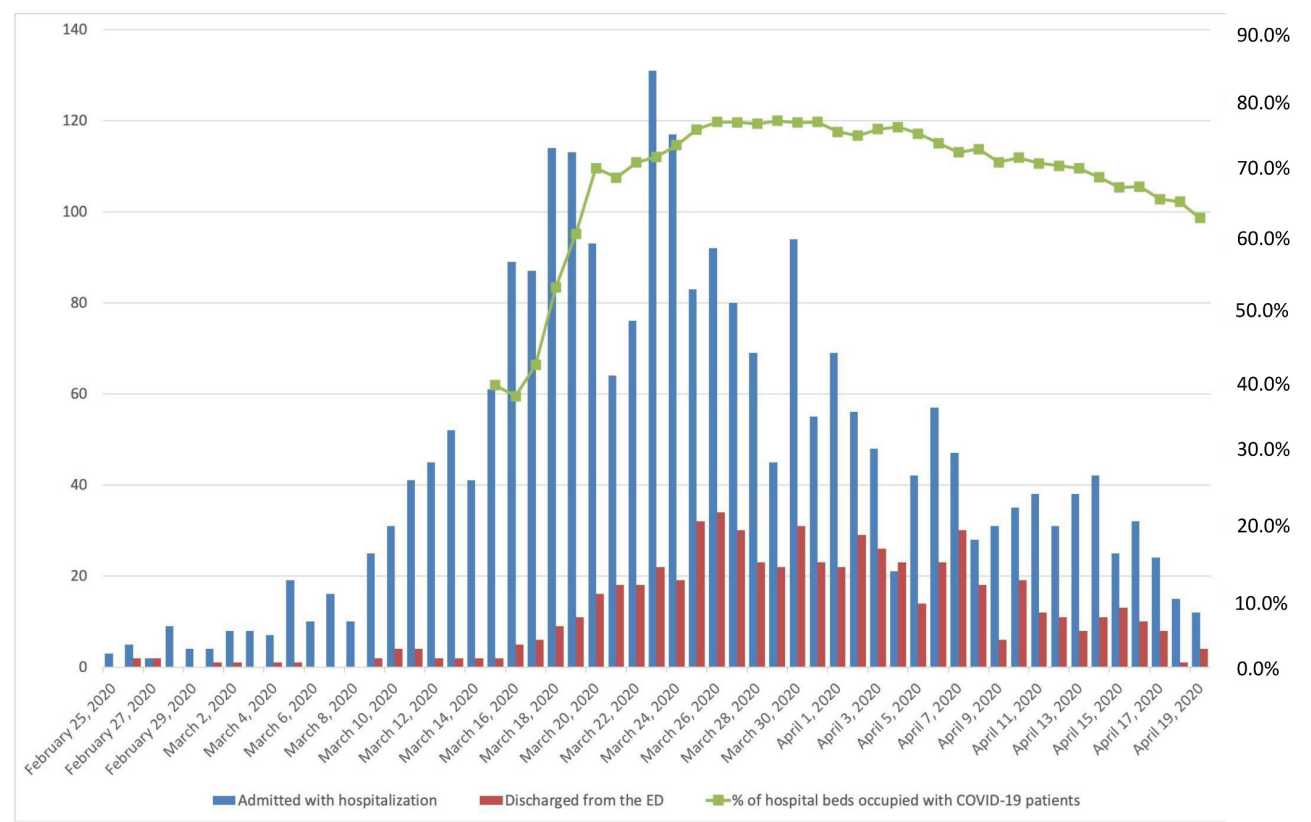

Figure 1. Patients treated by the emergency department per day between 25 February 2020, and 19 April 2020. The blue lines indicate patients admitted and hospitalized, and the red lines indicate patients discharged from the emergency department. The green line represents the percentage of hospital beds (including ICU) occupied by patients with COVID-19.

The median time from clinical onset to hospital admission was 6 days (IQR, 3-9). At admission, the patients had a median age of 61 (IQR, $46-78$ ) years, $52 \%$ were women, $41 \%$ had arterial hypertension, $19 \%$ had chronic heart disease, and $17 \%$ had diabetes mellitus. The most common symptoms at admission were fever, cough and dyspnea, and the median oxygen saturation at admission was 95\% (IQR, 92-97). The most common complications during hospitalization were acute confusional syndrome, acute kidney failure and acute respiratory distress syndrome (Table 1).

Table 1. Characteristics at admission and complications during hospitalization.

\begin{tabular}{|c|c|c|c|c|}
\hline Variable & $\begin{array}{c}\text { Total } \\
(N=2226)\end{array}$ & $\begin{array}{l}\text { Deaths } \\
(N=460)\end{array}$ & $\begin{array}{l}\text { Live Discharges } \\
\quad(N=1766)\end{array}$ & $p$-Value \\
\hline Median age, years (IQR) & $61(46-78)$ & $82.5(76-87)$ & $56(42-71)$ & $<0.001(\mathrm{w})$ \\
\hline Sex, $n(\%)$ & & & & $<0.001$ \\
\hline Male & $1074(48.2)$ & $286(62.2)$ & $788(44.6)$ & \\
\hline Female & $1152(51.8)$ & $174(37.8)$ & $978(55.4)$ & \\
\hline Nursing home resident, $n(\%)$ & 709 (31.9) & $125(27.2)$ & $584(33.1)$ & 0.018 \\
\hline Current smokers, $n(\%)$ & $157(7.1)$ & $44(9.6)$ & $113(6.4)$ & 0.023 \\
\hline Comorbidities (at least one), $n$ (\%) & $1747(78.5)$ & $448(97.4)$ & $1299(73.6)$ & $<0.001$ \\
\hline Arterial hypertension & $920(41.3)$ & $318(69.1)$ & $602(34.1)$ & $<0.001$ \\
\hline Chronic heart disease & $429(19.3)$ & $195(42.4)$ & $234(13.3)$ & $<0.001$ \\
\hline Diabetes mellitus & $381(17.1)$ & $157(34.1)$ & $224(12.7)$ & $<0.001$ \\
\hline Rheumatological disease & $268(12.0)$ & $80(17.4)$ & $188(10.6)$ & $<0.001$ \\
\hline Solid malignant disease & $252(11.3)$ & $93(20.2)$ & $159(9.0)$ & $<0.001$ \\
\hline Obesity & $242(10.9)$ & $66(14.3)$ & $176(10.0)$ & 0.009 \\
\hline Chronic kidney disease & $174(7.8)$ & $94(20.4)$ & $80(4.5)$ & $<0.001$ \\
\hline Chronic obstructive pulmonary disease & $153(6.9)$ & $65(14.1)$ & $88(5.0)$ & $<0.001$ \\
\hline Other chronic lung diseases & $143(6.4)$ & $49(10.7)$ & $94(5.3)$ & $<0.001$ \\
\hline Hematological malignant disease & $133(6.0)$ & $46(10.0)$ & $87(4.9)$ & $<0.001$ \\
\hline Asthma & $115(5.2)$ & $17(3.7)$ & $98(5.5)$ & 0.138 \\
\hline Liver disease & $89(4.0)$ & $23(5.0)$ & $66(3.7)$ & 0.272 \\
\hline HIV infection & $13(0.6)$ & $4(0.9)$ & $9(0.5)$ & 0.3218 (f) \\
\hline
\end{tabular}


Table 1. Cont.

\begin{tabular}{|c|c|c|c|c|}
\hline Variable & $\begin{array}{c}\text { Total } \\
(N=2226)\end{array}$ & $\begin{array}{l}\text { Deaths } \\
(N=460)\end{array}$ & $\begin{array}{l}\text { Live Discharges } \\
\qquad(N=1766)\end{array}$ & $p$-Value \\
\hline \multicolumn{5}{|l|}{ Symptoms on admission, $n(\%)$} \\
\hline Fever & 1585 (71.2) & $325(70.7)$ & $1260(71.3)$ & 0.814 \\
\hline Cough & $1373(61.7)$ & $228(49.6)$ & $1145(64.8)$ & $<0.001$ \\
\hline Dyspnea & $1108(49.8)$ & $278(60.4)$ & $830(47.0)$ & $<0.001$ \\
\hline Myalgia & $596(26.8)$ & $51(11.1)$ & $545(30.9)$ & $<0.001$ \\
\hline Diarrhea & $484(21.7)$ & $62(13.5)$ & $422(23.9)$ & $<0.001$ \\
\hline Headache & $427(19.2)$ & $24(5.2)$ & $403(22.8)$ & $<0.001$ \\
\hline Sputum production & $320(14.4)$ & $80(17.4)$ & $240(13.6)$ & 0.046 \\
\hline Nausea or vomiting & $299(13.4)$ & $42(9.1)$ & $257(14.6)$ & 0.003 \\
\hline Anosmia & $284(12.8)$ & $5(1.1)$ & $279(15.8)$ & 0.003 \\
\hline \multicolumn{5}{|l|}{ Respiratory status } \\
\hline Median $\mathrm{SatO}_{2}$ on admission, \% (IQR) & $95(92-97)$ & $90(85-93.3)$ & $96(93-97)$ & $<0.001(w)$ \\
\hline SatO $_{2}<90 \%$ on admission, $n(\%)$ & $234(10.5)$ & $126(27.4)$ & $108(6.1)$ & $<0.001$ \\
\hline $\begin{array}{l}\text { Median time from disease onset to } \\
\text { hospital admission, days (IQR) }\end{array}$ & $6(3-9)$ & $4(2-7)$ & $7(3-10)$ & $<0.001(w)$ \\
\hline \multicolumn{5}{|l|}{ Complications during hospitalization } \\
\hline Acute confusional syndrome & $197(8.8)$ & $149(32.4)$ & $48(2.7)$ & $<0.001$ \\
\hline Acute kidney failure & $173(7.8)$ & $120(26.1)$ & $53(3.0)$ & $<0.001$ \\
\hline Acute respiratory distress syndrome & $109(4.9)$ & $94(20.4)$ & $15(0.8)$ & $<0.001$ \\
\hline Bacterial pneumonia & $64(2.9)$ & $45(9.8)$ & $19(1.1)$ & $<0.001$ \\
\hline Acute heart failure & $51(2.3)$ & $34(7.4)$ & $17(1.0)$ & $<0.001$ \\
\hline Arrhythmia & $46(2.1)$ & $33(7.2)$ & $12(0.7)$ & $<0.001$ \\
\hline \multicolumn{5}{|l|}{ Treatment regimens, $n(\%)$} \\
\hline Hydroxychloroquine + azithromycin & $706(31.7)$ & $180(39.1)$ & $526(29.8)$ & $<0.001$ \\
\hline Hydroxychloroquine & $545(24.5)$ & $163(35.4)$ & $382(21.6)$ & $<0.001$ \\
\hline $\begin{array}{l}\text { Hydroxychloroquine }+ \\
\text { lopinavir/ritonavir }\end{array}$ & $116(5.2)$ & $23(5.0)$ & $93(5.3)$ & 0.911 \\
\hline $\begin{array}{l}\text { Hydroxychloroquine }+ \text { azithromycin }+ \\
\text { lopinavir/ritonavir }\end{array}$ & $69(3.1)$ & $23(5.0)$ & $46(2.6)$ & 0.012 \\
\hline Lopinavir/ritonavir & $19(0.8)$ & $3(0.6)$ & $16(0.9)$ & $0.216(f)$ \\
\hline
\end{tabular}

Abbreviations: (f), Fisher's Exact Test; HIV, human immunodeficiency virus; IQR, interquartile range; $\mathrm{SatO}_{2}$, oxygen saturation; (w), Wilcoxon Rank Sum Test.

Most of the patients were treated with drugs presumed to have antiviral activity against SARS-CoV-2. The most frequent combination was hydroxychloroquine plus azithromycin followed by hydroxychloroquine in isolation.

At the time of the analysis, 237 patients had been admitted to the ICU, 116 remained in the ICU, 55 had died, 20 were discharged from the hospital, and 46 remained confined to a standard hospital bed. Table 2 shows the demographic characteristics, comorbidities and respiratory status on the day of emergency department admission of the 75 patients (3.4\%) transferred to the ICU who had died or been discharged by April 19. Compared with the entire cohort, the patients admitted to the ICU were older (median age, 64 vs. 61 years), had a higher male/female ratio (3.2 vs. 0.93) and had a higher prevalence of arterial hypertension ( 52 vs. $41.3 \%$ ), obesity ( $30.7 \%$ vs. $10.9 \%)$, diabetes mellitus $(28.0 \%$ vs. $17.1 \%)$ and chronic obstructive pulmonary disease (17.3\% vs. $6.9 \%)$. 
Table 2. Demographics, Comorbidities and Respiratory Status on Admission of the Intensive Care Patients.

\begin{tabular}{|c|c|c|c|c|}
\hline Variable & $\begin{array}{c}\text { Total } \\
(N=75)\end{array}$ & $\begin{array}{l}\text { Deaths } \\
(N=55)\end{array}$ & $\begin{array}{l}\text { Live Discharges } \\
\quad(N=20)\end{array}$ & $p$-Value \\
\hline Median age, years (IQR) & $64(54-71)$ & $69(62-72.5)$ & $47(38.5-56)$ & $<0.001(w)$ \\
\hline Sex, $n(\%)$ & & & & 0.127 (f) \\
\hline Male & $57(76)$ & 39 (70.9) & $18(90)$ & \\
\hline Female & $18(24)$ & $16(29.1)$ & $2(10)$ & \\
\hline Current smokers, $n(\%)$ & $10(13.3)$ & $7(12.7)$ & $3(15)$ & $1.000(f)$ \\
\hline Comorbidities (at least one), $n(\%)$ & $67(89.3)$ & $52(94.6)$ & $15(75)$ & 0.045 \\
\hline Arterial hypertension & $39(52.0)$ & $32(58.2)$ & $7(35)$ & 0.130 \\
\hline Obesity & $23(30.7)$ & $18(32.7)$ & $5(25)$ & 0.719 \\
\hline Diabetes mellitus & $21(28.0)$ & $17(30.9)$ & $4(20)$ & 0.401 (f) \\
\hline Chronic obstructive pulmonary disease & $13(17.3)$ & $12(21.8)$ & $1(5)$ & 0.165 (f) \\
\hline Chronic heart disease & $11(14.7)$ & $10(18.2)$ & $1(5)$ & 0.269 (f) \\
\hline Solid malignant disease & $9(12.0)$ & $6(10.9)$ & $3(15)$ & 0.693 (f) \\
\hline Rheumatological disease & $7(9.3)$ & $5(9.1)$ & $2(10)$ & $1.000(f)$ \\
\hline Chronic kidney disease & $5(6.7)$ & $5(9.1)$ & $0(0)$ & 0.316 (f) \\
\hline Asthma & $4(5.3)$ & $3(5.5)$ & $1(5)$ & $1.000(\mathrm{f})$ \\
\hline Other chronic lung diseases & $4(5.3)$ & $4(7.3)$ & $0(0)$ & $0.568(\mathrm{f})$ \\
\hline Liver disease & $3(4.0)$ & $2(3.6)$ & $1(5)$ & $1.000(\mathrm{f})$ \\
\hline Hematological malignant disease & $3(4.0)$ & $3(5.5)$ & $0(0.0)$ & 0.560 (f) \\
\hline HIV infection & $1(1.3)$ & $1(1.8)$ & $0(0)$ & 1.000 (f) \\
\hline Respiratory status, $n(\%)$ & & & & \\
\hline $\mathrm{SatO}_{2}<90 \%$ on admission & $11(17)$ & $9(16.3)$ & $2(10)$ & $0.717(\mathrm{f})$ \\
\hline
\end{tabular}

Abbreviations: (f), Fisher's Exact Test; HIV, human immunodeficiency virus; IQR, interquartile range; $\mathrm{SatO}_{2}$, oxygen saturation; (w), Wilcoxon Rank Sum Test.

Table 3 shows the mortality by age group and sex for the 2226 patients. The overall mortality was $26.6 \%$ for the men and $15.1 \%$ for the women. Mortality increased with age, reaching over $60 \%$ for patients over 80 years of age.

Table 3. Mortality distribution by age group and sex.

\begin{tabular}{ccccccc}
\hline \multirow{2}{*}{ Age Group } & \multicolumn{2}{c}{ Male } & \multicolumn{2}{c}{ Female } & \multicolumn{2}{c}{ Total } \\
\cline { 2 - 7 } & $\boldsymbol{N}$ & Mortality, $\%$ & $\boldsymbol{N}$ & Mortality, \% & $\boldsymbol{N}$ & Mortality, \% \\
\hline 18-29 years & 59 & 0.0 & 100 & 1.0 & 159 & 0.6 \\
30-39 years & 86 & 0.0 & 133 & 0.0 & 219 & 0 \\
40-49 years & 120 & 1.7 & 167 & 1.2 & 287 & 1.5 \\
50-59 years & 166 & 4.8 & 199 & 3.0 & 365 & 3.8 \\
60-69 years & 120 & 20.0 & 152 & 7.9 & 327 & 11 \\
70-79 years & 202 & 41.1 & 156 & 25.0 & 358 & 34.1 \\
80-89 years & 212 & 62.7 & 179 & 41.3 & 391 & 52.9 \\
$\geq 90$ years & 54 & 66.7 & 66 & 60.6 & 120 & 63.3 \\
\hline
\end{tabular}

Table 4 shows the laboratory findings at admission for the entire cohort and for the ICU subgroup. In the cohort, the baseline creatine kinase, creatinine, D-dimer, ferritin, lactate dehydrogenase, procalcitonin, C-reactive protein and high-sensitivity cardiac troponin I levels and prothrombin times were higher among the non-survivors than the survivors. In the cohort admitted to the ICU, the most notable differences with the whole cohort were higher levels of $\mathrm{D}$-dimer, ferritin, $\mathrm{C}$ reactive protein and troponin. Within the ICU cohort, the lymphocyte counts and procalcitonin and C-reactive protein levels at hospital admission were also clearly higher in the patients who died compared with those who survived. 
Table 4. Laboratory findings on admission.

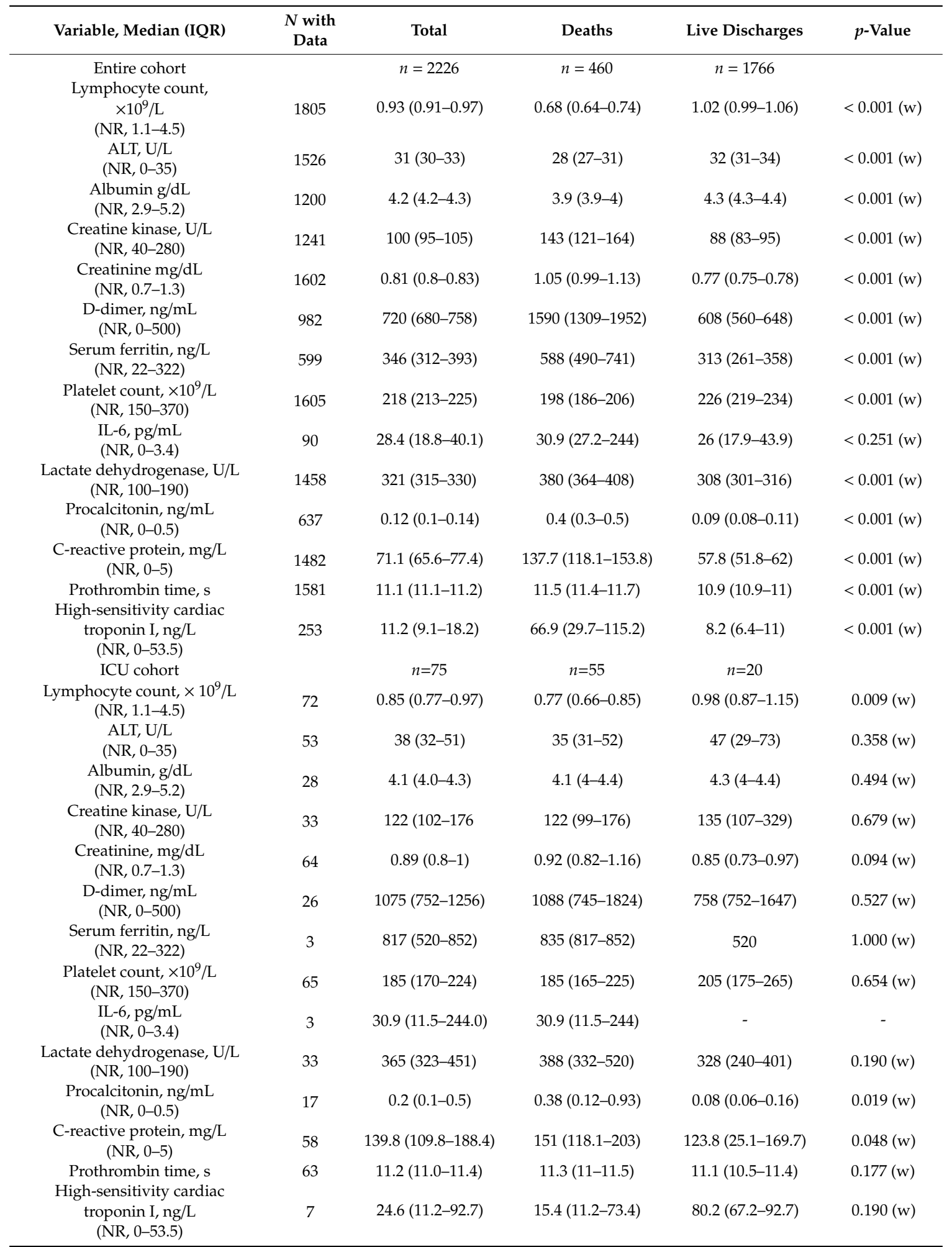

Abbreviations: ALT, alanine aminotransferase; ICU, intensive care unit; IL, interleukin; IQR, interquartile range; NR, normal range.

In the multivariable logistic regression model, we found that male sex, older age, an oxygen saturation $<90 \%$ on admission, lower lymphocyte count and high C-reactive protein levels were associated with a high probability of death (Table 5). 
Table 5. Risk factors associated with in-hospital death.

\begin{tabular}{ccc}
\hline Variable & Multivariate OR (95\% CI) & $p$-Value \\
\hline Age, years & $1.105(1.087-1.124)$ & $<0.001$ \\
Sex, female & $0.547(0.375-0.794)$ & 0.002 \\
$\mathrm{SatO}_{2}<90 \%$ & $3.805(2.539-5.723)$ & $<0.001$ \\
Lymphocyte count, $\times 10^{9} / \mathrm{L}$ & $0.573(0.356-0.879)$ & 0.017 \\
C-reactive Protein, $\mathrm{mg} / \mathrm{L}$ & $1.006(1.003-1.008)$ & $<0.001$ \\
\hline
\end{tabular}

Abbreviations: $\mathrm{SatO}_{2}$, oxygen saturation.

\section{Discussion}

To the best of our knowledge, this is the first report of a large cohort of patients hospitalized with COVID-19 in Europe. Our cohort includes all patients with a final outcome (discharge or death) consecutively admitted to our hospital during the worst phase of COVID-19 in Madrid's hospital system.

Similar to other cohorts [9-15], the hospitalized patients in Madrid were elderly and had numerous comorbidities, the most common of which were arterial hypertension and diabetes. Our male/female ratio was 0.9 , which is lower than the 1.5 reported in the series from Wuhan (China) [12] and New York City [10]. In Madrid, the male/female ratio for individuals older than 60 and 75 years was 0.74 and 0.61 , respectively [16]. Differences compared with other cohorts could be partially explained by the different male/female ratio in the Madrid population pyramid. Despite our lower male/female ratio compared with other reports, the mortality for each age group was notably higher for the male patients than for the female patients, as reported in other cohorts. It is relevant that one third of the patients included in our cohort were nursing homes residents.

The overall mortality $(20.7 \%)$ in our series by age group was similar to that of the New York cohort (21\%) [10] and lower than that of a Wuhan cohort (28.3\%) [12]. In our cohort, older age and the presence of comorbidities were more common among the patients with fatal outcomes, both for the entire cohort and for those admitted to the ICU.

The most frequent symptoms at admission were fever, cough and dyspnea; myalgia and diarrhea were also common. Notably, $12.8 \%$ of the patients had anosmia as a presenting symptom, as described in other cohorts [17]. The time from disease onset was short (6 days), and the patients' respiratory status on admission (as reflected by oxygen saturation) was generally poor, with half of the patients presenting an oxygen saturation of $<95 \%$. General symptoms, such as diarrhea, myalgia, headache and anosmia, were more common among survivors, while respiratory symptoms such as dyspnea and sputum production were more prevalent among the non-survivors, who also had a lower median oxygen saturation on admission ( $90 \%$ vs. $96 \%$ ). In any case, these findings need to be confirmed in other large cohorts and meta-analyses.

The laboratory values on admission were consistent with an impaired immune-inflammatory profile, characterized by lymphopenia and elevated D-dimer, procalcitonin, ferritin and C-reactive protein levels. Most of these abnormal laboratory readings were more common in the patients with fatal outcomes. Creatine kinase and troponin levels on admission were also higher in the patients with fatal outcomes, a finding also reported in other series [18].

Most of our patients underwent treatments presumed to have activity against SARS-CoV-2. The indication for treatment in Spain has changed during the course of the pandemic but has always been based on the indications by the Spanish Ministry of Health and the availability of treatments. Our hospital has also participated in several clinical trials, the results of which we cannot provide in this manuscript (remdesivir, tocilizumab, sarilumab). We have included in this article the use of treatments with potentially antiviral effects available in our hospital but that have not been included in a clinical trial (hydroxychloroquine, azithromycin and lopinavir/ritonavir). It is also noteworthy that, at the start of the pandemic in Spain, only symptomatic treatment was indicated. At present, there are 
no clinical trial data that support the use of any of these treatments for improving the outcomes of patients with COVID-19.

This study has a number of limitations. First, the data were collected from various databases, both manually and automatically. The data manually entered into the eCRF were monitored and curated. Second, we did not conduct a follow-up of the patients after discharge. Third, our reported mortality rates might change once the entire cohort of hospitalized patients has been analyzed.

In summary, this study provides initial data on the clinical and laboratory features and outcomes of patients hospitalized with COVID-19 infection in a large teaching hospital in Madrid during the peak of the pandemic in Spain.

Supplementary Materials: The following are available online at http://www.mdpi.com/2077-0383/9/6/1733/s1, 1. COVID@HULP Working Group list of members and Acknowledgments, 2. Electronic case record form (eCRF).

Author Contributions: Conceptualization, A.M.B., A.J.C., E.R. and J.R.A.; Data curation, J.M.-V., M.Q., A.M.-V., G.M.-A. and D.P.A.; Formal analysis, A.M.B., A.J.C., J.M.-V., E.R. and J.F.; Investigation, A.M.B., F.A., R.Á.-S., J.M.-V., M.Q., J.C.F., R.M.T.S.-O., J.G.-R., A.M.-V., A.B., E.R., G.M.-A., N.G.-A., M.C.N., M.M.-d.-G., F.M.R., F.R.-B., A.M.-Q., A.R.N., J.M., C.J.C.S. and J.F.; Methodology, A.M.B., A.J.C., E.R., G.M.-A., J.F. and J.R.A.; Supervision, A.M.B., M.Q., E.R.C., C.P.S., J.J.R. and J.R.A.; Validation, J.F.; Visualization, J.R.A.; Writing - original draft, A.M.B., A.J.C., E.R. and J.F.; Writing - review \& editing, A.M.B., A.J.C., E.R., M.A.H., J.F. and J.R.A. All authors have read and agreed to the published version of the manuscript.

Funding: This research received no external funding.

Acknowledgments: We thank all La Paz Hospital staff, whose selfless dedication is allowing us to face the worst healthcare challenge of our history. We also want to acknowledge Hospital Management for its support to the Covid@HULP project.

Conflicts of Interest: The authors declare no conflict of interest.

\section{References}

1. Spiteri, G.; Fielding, J.; Diercke, M.; Campese, C.; Enouf, V.; Gaymard, A.; Bella, A.; Sognamiglio, P.; Moros, M.J.S.; Riutort, A.N.; et al. First cases of coronavirus disease 2019 (COVID-19) in the WHO European Region, 24 January to 21 February 2020. Eurosurveillance 2020, 25. [CrossRef] [PubMed]

2. Instituto Nacional de Estadística. Población Residente por Fecha, Sexo y Edad. Madrid, España. Available online: https://www.ine.es/jaxiT3/Tabla.htm?t=9663\&L=0 (accessed on 26 April 2020).

3. Centro de Coordinación de Alertas y Emergencias Sanitarias. Enfermedad por el Coronavirus (COVID-19). España: Ministerio de Sanidad. Available online: https://www.mscbs.gob.es/profesionales/saludPublica/ ccayes/alertasActual/nCov-China/situacionActual.htm (accessed on 26 April 2020).

4. COVID-19. Situación Actual en la Comunidad de Madrid. Informe de Situación del 27 de Abril. Available online: https://www.comunidad.madrid/sites/default/files/doc/sanidad/200425_cam_covid19.pdf (accessed on 26 April 2020).

5. Ministero della Salute. Covid-19, i casi in Italia il 25 Aprile ore 18. Available online: http://www.salute.gov.it/ imgs/C_17_notizie_4605_0_file.pdf (accessed on 26 April 2020).

6. New York City Health. COVID-19: Data. Available online: https://www1.nyc.gov/site/doh/covid/covid-19data.page (accessed on 26 April 2020).

7. Novel Coronaviris ( $\mathrm{nCoV}$ ) Acute Respiratory Infection Clinical Characterisation Data Tools. nCoV Case Records Form Version 1.3. 24 Feb 2020. Adapted from Sprint Sari Case Report form by ISARIC. Available online: https://media.tghn.org/medialibrary/2020/03/ISARIC_COVID-19_CRF_V1.3_24Feb2020.pdf (accessed on 16 February 2020).

8. R Core Team. R: A Language and Environment for Statistical Computing; R Foundation for Statistical Computing: Vienna, Austria. Available online: https://www.R-project.org. (accessed on 10 April 2020).

9. Goyal, P.; Choi, J.J.; Pinheiro, L.C.; Schenck, E.J.; Chen, R.; Jabri, A.; Satlin, M.J.; Campion, T.R., Jr.; Nahid, M.; Ringel, J.B.; et al. Clinical Characteristics of Covid-19 in New York City. New Engl. J. Med. 2020. [CrossRef] [PubMed] 
10. Richardson, S.; Hirsch, J.S.; Narasimhan, M.; Crawford, J.M.; McGinn, T.; Davidson, K.W.; Barnaby, D.P.; Becker, L.B.; Chelico, J.D.; Cohen, S.L.; et al. Presenting Characteristics, Comorbidities, and Outcomes Among 5700 Patients Hospitalized With COVID-19 in the New York City Area. JAMA 2020. [CrossRef] [PubMed]

11. Garg, S.; Kim, L.; Whitaker, M.; O’Halloran, A.; Cummings, C.; Holstein, R.L.; Prill, M.; Chai, S.J.; Kirley, P.D.; Alden, N.B.; et al. Hospitalization rates and characteristics of patients hospitalized with laboratory-confirmed coronavirus disease 2019-COVID-NET, 14 States, 1-30 March 2020. MMWR Morb. Mortal. Wkly. Rep. 2020, 69, 458-464. [CrossRef] [PubMed]

12. Zhou, F.; Yu, T.; Du, R.; Fan, G.; Liu, Y.; Liu, Z.; Xiang, J.; Wang, Y.; Song, B.; Gu, X.; et al. Clinical course and risk factors for mortality of adult inpatients with COVID-19 in Wuhan, China: A retrospective cohort study. Lancet 2020, 395, 1054-1062. [CrossRef]

13. Wang, D.; Hu, B.; Hu, C.; Zhu, F.; Liu, X.; Zhang, J.; Wang, B.; Xiang, H.; Cheng, Z.; Xiong, Y.; et al. Clinical Characteristics of 138 Hospitalized Patients With 2019 Novel Coronavirus-Infected Pneumonia in Wuhan, China. JAMA 2020. [CrossRef] [PubMed]

14. Huang, C.; Wang, Y.; Li, X.; Ren, L.; Zhao, J.; Hu, Y.; Zhang, L.; Fan, G.; Xu, J.; Gu, X.; et al. Clinical features of patients infected with 2019 novel coronavirus in Wuhan, China. Lancet 2020, 395, 497-506. [CrossRef]

15. Guan, W.J.; Ni, Z.Y.; Hu, Y.; Liang, W.H.; Ou, C.Q.; He, J.X.; Liu, L.; Shan, H.; Lei, C.L.; Hui, D.S.; et al. Clinical Characteristics of Coronavirus Disease 2019 in China. N. Engl. J. Med. 2020. [CrossRef] [PubMed]

16. Centro Internacional sobre el Envejecimiento. Estimaciones de la Población de la Provincia de Madrid. España. Available online: https://cenie.eu/es/observatorio/demografia/madrid (accessed on 26 April 2020).

17. Spinato, G.; Fabbris, C.; Polesel, J.; Cazzador, D.; Borsetto, D.; Hopkins, C.; Boscolo-Rizzo, P. Alterations in smell or taste in mildly symptomatic outpatients with SARS-CoV-2 infection. JAMA 2020. [CrossRef] [PubMed]

18. Shi, S.; Qin, M.; Shen, B.; Cai, Y.; Liu, T.; Yang, F.; Gong, W.; Liu, X.; Liang, J.; Zhao, Q.; et al. Association of cardiac injury with mortality in hospitalized patients with COVID-19 in Wuhan, China. JAMA Cardiol. 2020. [CrossRef] [PubMed]

(C) 2020 by the authors. Licensee MDPI, Basel, Switzerland. This article is an open access article distributed under the terms and conditions of the Creative Commons Attribution (CC BY) license (http://creativecommons.org/licenses/by/4.0/). 